\title{
MOLECULAR EPIDEMIOLOGY OF TUBERCULOSIS IN THE CZECH REPUBLIC, 2004: ANALYSIS OF M. TUBERCULOSIS COMPLEX ISOLATES ORIGINATING FROM THE CITY OF PRAGUE, SOUTH MORAVIA AND THE MORAVIAN-SILESIAN REGION
} \author{
Jarmila Kaustová6, Carolin Lechleitner ${ }^{1}$, Milan Kubín ${ }^{2}$ \\ Austria \\ ${ }^{2}$ Institute of Hygiene of the City of Prague, Czech Republic \\ ${ }^{3}$ Metropolitan Institute of Public Health, Prague, Czech Republic \\ ${ }^{4}$ KlinLab s. r. o. Prague, Czech Republic \\ ${ }^{5}$ Regional Institute of Public Health, Brno, Czech Republic \\ ${ }^{6}$ Regional Institute of Public Health, Ostrava, Czech Republic
}

Wolfgang M. Prodinger ${ }^{1}$, Vladimír Polanecký ${ }^{2}$ Bohumila Kozáková ${ }^{3}$, Maria Müllerová4, Lev Mezenskýs,

${ }^{1}$ Dept. of Hygiene, Microbiology and Social Medicine, Division of Hygiene and Medical Microbiology, Innsbruck Medical University, Innsbruck,

\section{SUMMARY}

Objectives: To compare M. tuberculosis complex genotypes from representative regions of the Czech Republic in order to estimate changes in strain prevalence and in the extent of imported drug-resistant tuberculosis.

Methods: Primary M. tuberculosis complex isolates $(n=155)$ and follow-up isolates $(n=15)$ from 155 patients from the first half of 2004 (98 from Prague, 37 from South Moravia and 35 from the Moravian-Silesian region) were genotyped by IS6110-RFLP, spoligotyping, and partly by VNTR-genotyping.

Results: Based on IS6110-RFLP, 110 of $155(71 \%)$ primary isolates were unique. Forty-five isolates (29\%) were found in 15 clusters comprising two to six patients and all but one cluster were also discriminated by MIRU-VNTR-genotyping. Four clusters comprised patients from different regions, and six were ongoing for several years. An indication of MDR-strain transmission was found in one instance. All four Beijing-type isolates with any resistance were associated with immigration from Eastern Europe.

Conclusions: The molecular epidemiological data of this period-prevalence, population based study and its comparison to earlier investigations point to a low extent of clustering between M. tuberculosis complex isolates in representative regions of the Czech Republic. Few clusters extending geographically and/or over several years were identified, providing a means for an in-depth analysis of risk factors of transmission. Beijing genotype isolates were shown to increase in prevalence to reach 6.5\%. Drug resistant isolates of this genotype were associated with immigration of from Eastern Europe, although direct transmission of a resistant isolate was probable only in one of eleven cases.

Key words: tuberculosis, fingerprinting, epidemiology, Beijing-genotype

Address for correspondence: Wolfgang M. Prodinger, Dept. of Hygiene, Microbiology and Social Medicine, Innsbruck Medical University Fritz-Pregl-Str. 3, A-6020 Innsbruck, Austria. E-mail: wolfgang.prodinger@i-med.ac.at

\section{INTRODUCTION}

Molecular methods to study the epidemiology of tuberculosis have become common, since IS6110 restriction fragment length polymorphism (RFLP) for Mycobacterium tuberculosis was introduced in 1993 (32). Both the understanding of the natural history of tuberculosis (TB) and the clarification of transmission chains have been advanced through such molecular epidemiological studies (33). Based on genotyping studies, some strainfamilies, in particular the Beijing genotype, were postulated to be associated with higher pathogenicity $(1,8)$, and partly also with evolving drug resistance $(8,13)$. As a consequence, the introduction of multidrug-resistant (MDR) TB from countries of the former Soviet Union has become a constant threat for Central European countries like the Czech Republic (8, 12, 19, 21). E. g., the proportion of notified cases of TB in foreigners in the Czech Republic has increased from $5.9 \%$ in 1997 to $14.1 \%$ in 2004. Of the latter, patients from the neighbouring country Ukraine $(\mathrm{n}=45)$ represented $30 \%(3)$.

Molecular analyses of $M$. tuberculosis complex isolates, primarily IS6110-RFLP, have been employed in the Czech Republic on several instances, starting with a point-prevalence investigation of isolates from the City of Prague (14). Further studies focussed on a MDR-TB microepidemic (16), on TB in prisoners $(16,20)$, and on TB transmission in South Moravia, an area of particularly low TB incidence (17). The spoligotyping method (9) was employed 
to study the prevalence of strains families, especially the Beijing genotype, in Prague and South Moravia (18). A first comprehensive IS6110-RFLP analysis for the Czech M. tuberculosis population included 231 isolates or $73 \%$ and $90 \%$, respectively, of all culturepositive TB cases from Prague and South Moravia, respectively, occurring in 1998 (ref. 21). The results suggested a proportion of cases attributable to recent transmission similar to other Central European countries with low TB incidence rates, although a few clusters were shown to be prevalent in both study regions. Only sporadic importation of TB from foreigners was noted at that time.

The present study surveys the Czech $M$. tuberculosis population from the first half of 2004 from three representative regions: the City of Prague, South Moravia, and the Moravian-Silesian region. The study areas are geographically, demographically and epidemiologically different areas: the metropolitan area of Prague, the national capital, counts 1.2 million inhabitants and with 12.0 per 100,000 had the second highest TB incidence rate in the country in 2004 (ref. 2). For comparison, the incidence rates in 2004 were 10.3 for South Moravia and 9.6 for the Moravian-Silesian (2). From 1998 until 2004, Czech notification data have shown a stable number of MDR cases which has remained between 2 and 10 cases per year $(0.5$ and $2 \%$, respectively, of all tested patients isolates) (7). Several resistant or MDR isolates were included in this study, and for the first time genotyping data and drug sensitivity testing results were correlated on a national scale.

This analysis is still based on IS6110-RFLP. However, a forthcoming standard method for TB molecular epidemiology (22, 30, 31), mycobacterial interspersed repetetive units (MIRU) genotyping or - in more general terms - variable number tandem repeat (VNTR) genotyping, was applied for the first time to a representative sample of Czech isolates. This should allow connecting previous with contemporary data.

\section{MATERIAL AND METHODS}

\section{Patients' Demographic Characteristics}

Data were collected by the culturing laboratories and checked against the notification reports of TB cases in the Czech Republic. Depersonalized initials were used outside the respective culturing laboratory to identify patients.

\section{M. tuberculosis Complex Isolates}

Isolates obtained by standard culturing techniques in one of the participating laboratory between January 1st and June 30th, 2004, were included in the study. For 15 patients, follow-up isolates were included as blinded internal controls thoughout the fingerprinting procedure. The identity as M. tuberculosis complex was confirmed by biochemical and/or genotypic tests. For genotyping, all isolates were subcultured on Loewenstein-Jensen medium. Drug-sensitivity testing for first line drugs was done by the proportion method on solid media according to standard techniques in the participating laboratories.

\section{Genotyping Procedures}

DNA fingerprinting was performed on subcultured isolates at the Innsbruck Medical University. Genomic DNA was isolated as described (32) and used for all fingerprinting methods. IS6110-RFLP was performed according to Van Embden et al.
(32) using the ECL Direct Nucleic Acid Labelling and Detection System (Amersham Biosciences, Chalfont, UK). The patterns were analyzed with Gelcompar ${ }^{\circledR}$ version 4.2 (Applied Math, Sint-Martens-Latem, Belgium) by the unweighted pair group method using arithmetic averages and the Dice coefficient for similarity with $1 \%$ band position tolerance. A cluster was defined as a group of isolates having an identical IS6110 -RFLP, cluster size was calculated by the $\mathrm{N}$ method, i.e. including the index case. Banding patterns from clusters found in the 1998 study (21) were compared manually to the patterns of cluster strains in this study, as different software had been employed in the earlier study. Spoligotyping was carried out according to Kamerbeek et al. (9) using first generation membranes (Isogen Bioscience BV, Maarsen, the Netherlands). The octal codes for spoligotypes were determined as proposed (5). Names for global spoligotypes are according to the international spoligotyping database SpolDB4 (4). MIRU-VNTR genotyping was performed on all RFLP-clustered isolates by 12 single PCRs as described (29), based on the method of Philip Supply $(22,30)$. MIRU copy numbers corresponding to the respective band size were taken from published copy number tables (www.ibl.fr/mirus/mirus.html). Six additional VNTR loci (VNTR numbers: 0424, 3690, 0577, 4156, 2401, 1982) were tested as described (31).

\section{RESULTS}

\section{Epidemiological Characteristics of Patients}

One hundred and ninety-two isolates from Prague, South Moravia, and the Moravian-Silesian region ( $\mathrm{n}=103$, 43, and 45, respectively) were submitted for genotyping. After correcting for isolates lost during recultivation or analysis and for the followup isolates, 170 isolates from 155 individuals were genotyped. The 155 patients recruited in 6 months represent $60.5 \%$ of all culture positive patients reported in these areas in the whole year 2004, and $23.3 \%$ of all Czech TB cases notified in that period, respectively (3). Basic demographic data of these individuals are displayed in Fig. 1 and Table 1. The mean age of all study patients was 51 years (range: $19-85$ years), female patients tended to be older than males. There was no gross difference in age distribution between the three study areas, although the male:female ratio, being 2.37 for all patients, was 3.63 in South Moravia. Twenty-nine patients (19\%) were born outside Czech or Slovak territory, and most foreign-born study patients were situated either

Table 1. Characteristics of 155 patients with genotyped M. tuberculosis complex isolates, according to region of origin, Czech Republic 2004

\begin{tabular}{|l|l|l|l|}
\hline $\begin{array}{l}\text { Geographic origin } \\
\text { of isolates }\end{array}$ & $\begin{array}{l}\text { All patients, } \\
\text { No. }\end{array}$ & $\begin{array}{l}\text { Mean age } \\
\text { (range) }\end{array}$ & Male: female ratio \\
\hline Prague & 83 & $\begin{array}{l}53 \\
(19-85)\end{array}$ & 1.96 \\
\hline South Moravia & 37 & $\begin{array}{l}47 \\
(18-82)\end{array}$ & 3.63 \\
\hline Moravian-Silesian region & 35 & $\begin{array}{l}51 \\
(24-88)\end{array}$ & 2.5 \\
\hline All & 155 & $\begin{array}{l}51 \\
(18-88)\end{array}$ & 2.37 \\
\hline
\end{tabular}




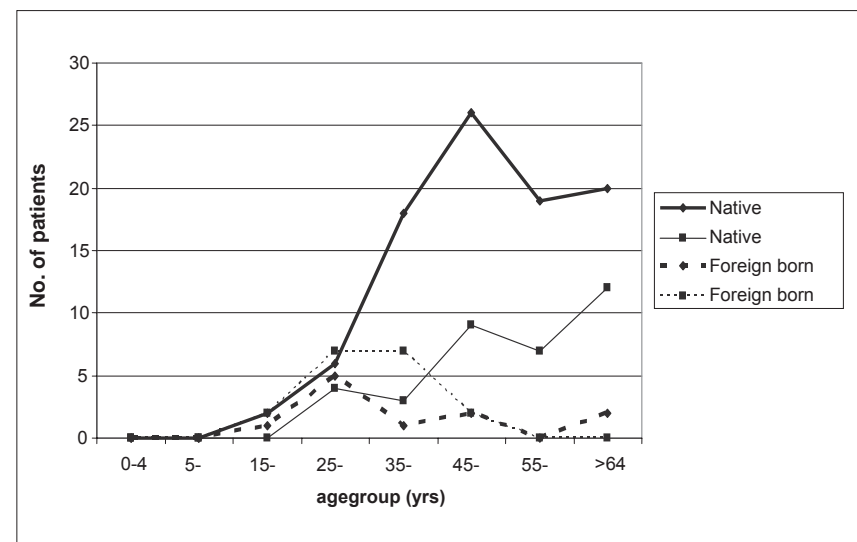

Fig. 1. Age distribution of 155 study patients according to sex and birthplace, Czech Republic, 2004.

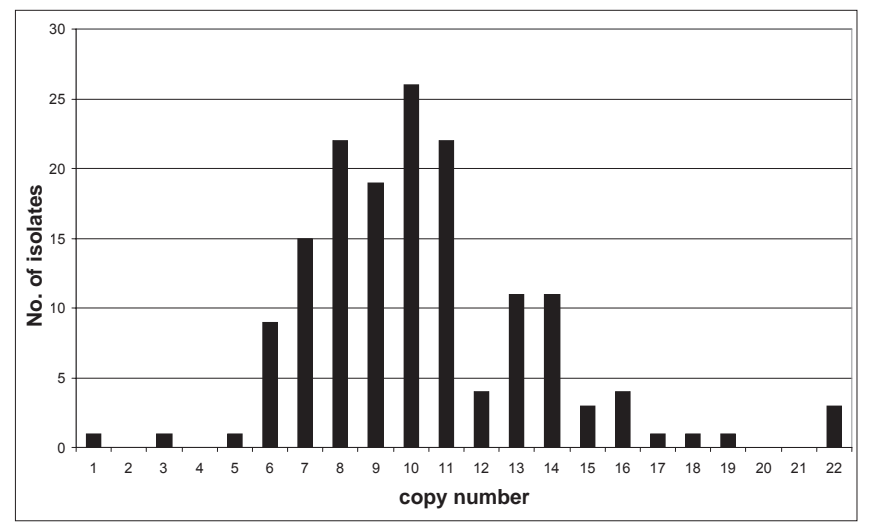

Fig. 2. Distribution of IS6110 copy numbers among 155 M. tuberculosis complex isolates from the Czech Republic, 2004.

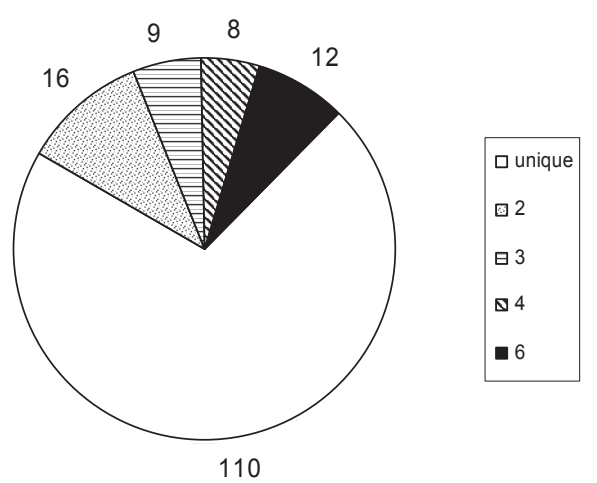

Fig. 3. Distribution of 155 M. tuberculosis complex isolates from the Czech Republic, 2004, into 15 clusters according to cluster size. Cluster size is calculated by including the index case ( $N$ method). The number of isolates per cluster size is indicated next to the pie sections.

in Prague $(\mathrm{n}=14)$ or in a district in the Moravian-Silesian region ( $n=9$; all asylum seekers). Foreign-born patients were significantly younger than native Czechs or Slovaks (Fig. 1). Homeless patients $(n=3)$ or patients in jail $(n=4)$ represented only small fractions. The demographic data of nine patients (all native Czechs and including one case of MDR-TB) whose isolates were lost during analysis were not significantly different from those of the patients with genotyped isolates.

\section{Cluster Analysis by IS6110 -RFLP}

All 170 isolates in the analysis were typeable by RFLP. Three isolates contained less than 6 copies of IS6110, but showed unique patterns. The 15 follow-up isolates that served as internal

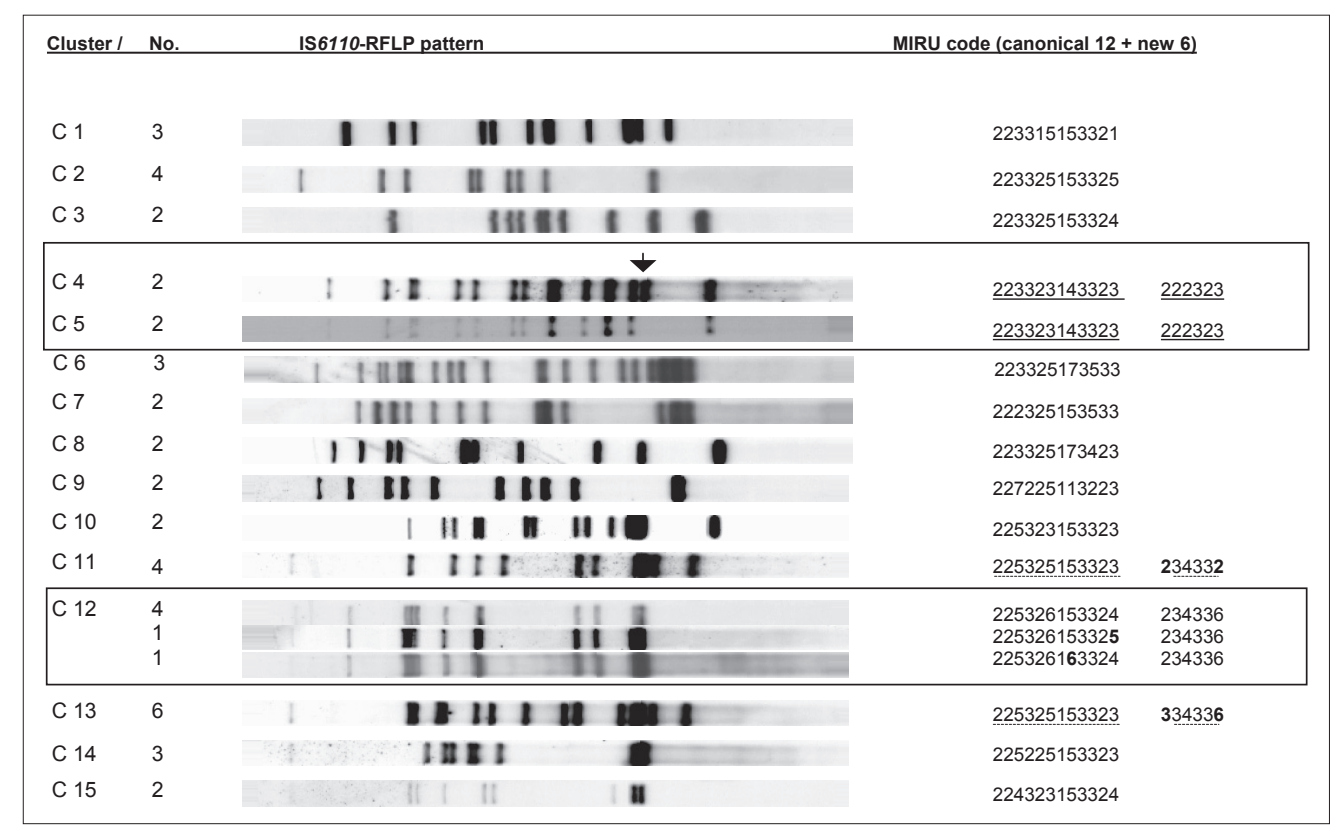

Fig. 4. IS6110-RFLP patterns and MIRU-VNTR codes for prototype isolates representing the 15 clusters (C1 through C15) found among $155 \mathrm{M}$. tuberculosis complex isolates from the Czech Republic, 2004. The number of isolates (n) per cluster is indicated. The MIRU code lists the copy numbers at the 12 canonical loci 2-4-10-16-20-23-24-26-27-31-39-40. For some isolates, six additional VNTR loci (sequentially: VNTR numbers 0424, 0577, 2401, 3690, 4156, and 1982) are given. Codes for different RFLP-clusters that were identical or nearly identical are underlined. The arrow points to the one band distinguishing C4 and C5. 
Table 2. Clustering by IS6110-RFLP of 155 patients' M. tuberculosis isolates, according to region of origin, Czech Republic 2004

\begin{tabular}{|l|l|l|l|l|l|}
\hline $\begin{array}{l}\text { Geographic origin } \\
\text { of isolates }\end{array}$ & $\begin{array}{l}\text { All isolates } \\
\text { collected for fingerprinting } \\
\text { including follow-ups }(\mathbf{n})\end{array}$ & $\begin{array}{l}\text { All typed isolates } \\
\text { excluding follow-ups } \\
\mathbf{( n )}\end{array}$ & $\begin{array}{l}\text { Isolates in RFLP } \\
\text {-based cluster } \\
\mathbf{n} \text { (\% of all) }\end{array}$ & $\begin{array}{l}\text { RFLP clusters (only } \\
\text { isolates with } \\
\text { this origin) (n) }\end{array}$ & $\begin{array}{l}\text { Minimal - maximal } \\
\text { number of isolates } \\
\text { per cluster }\end{array}$ \\
\hline Prague & 103 & 83 & $25(30.1 \%)$ & 5 & $2-6$ \\
\hline South Moravia & 43 & 37 & $11(29.7 \%)$ & 3 & $2-3$ \\
\hline $\begin{array}{l}\text { Moravian-Silesian } \\
\text { region }\end{array}$ & 35 & 35 & $9(25.7 \%)$ & 3 & 2 \\
\hline $\begin{array}{l}\text { Clusters with isolates } \\
\text { from }>1 \text { region }\end{array}$ & n.a. & n.a. & n.a. & 4 & $2-6$ \\
\hline All & 181 & 155 & $45(29 \%)$ & 15 & $2-6$ \\
\hline
\end{tabular}

The numbers for cluster isolates are given by the $\mathrm{N}$ method (i.e., including the index case); n.a., not applicable

controls for the reculturing and fingerprinting process yielded identical patterns for 14 pairs, and one pattern that differed by one additional faint band from that of the corresponding primary isolate. The IS6110 copy number among the 155 patients' isolates showed a distribution skewed to the right, with high-copy number isolates being of the Beijing genotype and the main peak centered around ten IS6110 copies (Fig. 2). This distribution was similar in all three regions (mean copy numbers range: 10.0 to 10.4), but different for clustered isolates (range $8-22$ copies, mean 12.1) and non-clustered ones (range 1 - 19 copies, mean 9.5).

Analysed together, the 155 patients' isolates were grouped into 110 individual types and 45 isolates found in 15 clusters, C1 through C15 (cluster size range: $2-6$; see Figs. 3 and 4) with a mean cluster size of 3 , including the index case in the calculation. Clustering rates in the three study areas ranged between 25.7 and $30.1 \%$, with an overall clustering rate of $29.0 \%$

Table 3. Most frequent (No. of isolates >2) and world-wide distributed shared types (ST) by spoligotyping among 155 patients' isolates from the Czech Republic, 2004

\begin{tabular}{|l|l|l|}
\hline ST name & Octal code & No. of isolates \\
\hline Haarlem3 & 777777777720771 & 29 \\
\hline T1 & 777777777760771 & 21 \\
\hline Beijing & 000000000003771 & 11 \\
\hline CZ-ST 1 & 677777777720771 & 9 \\
\hline Haarlem1 & 777777774020771 & 7 \\
\hline CZ-ST 2 & 774037777760700 & 5 \\
\hline CZ-ST 3 & 777777760000000 & 5 \\
\hline CZ-ST 4 & 777777743760771 & 4 \\
\hline T2 & 777777777760731 & 4 \\
\hline T3 & 777773777760771 & 4 \\
\hline CZ-ST 5 & 777777757777771 & 3 \\
\hline CZ-ST 6 & 777777807760771 & 3 \\
\hline Haarlem2 & 000000004020771 & 3 \\
\hline LAM7 & 777777404760771 & 1 \\
\hline Vietnam type & 777777774413771 & 1 \\
\hline
\end{tabular}

(Table 2). The three clusters that comprised more than 3 isolates were two clusters in Prague with 4 and 6 isolates, respectively, and one occurring in all three regions, also with 6 isolates. The latter and further three clusters comprising patients at more than one study region contributed one third (15 of 45) of all patients with clustered isolates. No statistically significant differences between patients with clustered isolates and patients with nonclustered isolates were found regarding sex, age, homelessness, or nationality. Czech or Slovak nationals were included in 14 of the 15 clusters, three of these included also foreign-born patients.

\section{Analysis by Spoligotyping}

Spoligotyping of all 170 isolates revealed 68 different spoligotypes, or shared types (STs) according to (4). Forty-five of the 68 STs were seen only once. All isolates clustered by IS6110-RFLP also shared the same ST. On the other hand, however, the STs associated with 14 of the 15 RFLP clusters were also found in non-clustered isolates. Eighty-one isolates (48 \% of all isolates) showed a world-wide encountered prototype ST, predominantly of the Haarlem, T or Beijing family (Table 3). Only 6 other STs, termed CZ-ST 1 through 6, were present in at least three isolates each, or in altogether 29 isolates (see Table 3).

\section{MIRU-VNTR Genotyping of Cluster Prototype Isolates}

For all 45 RFLP-clustered isolates the copy numbers for the twelve canonical MIRU-type VNTR loci were assessed. For 29 of these 45 isolates, i. e., for clusters with more than 3 isolates and for any clusters with an identical 12-loci profile, the copy numbers in six additional VNTR loci were determined. Fifteen different MIRU-VNTR combinations were found and their distribution was nearly congruent with RFLP clustering (see Fig. 4). Clusters C4 and C5 which differed by only one band were identical by all 18 VNTR loci. C11 and C13, clearly distinguishable by RFLP, were only separated by 2 out of 6 additional VNTR loci. Within cluster $\mathrm{C} 12,2$ of 6 isolates were minimally different by one copy in 1 of 18 loci.

\section{Correlation of Genotyping and Drug Sensitivity data}

Of 170 isolates, 158 had been found fully susceptible against first line drugs. For one isolate the DST result could not be procured, and 11 showed a resistant phenotype: 3 were resistant against INH, 3 against INH and SM, and 5 were MDR with the resistance patterns INH+RMP $(n=2), I N H+R M P+S M(n=2)$, 
Table 4. Occurrence of Beijing-genotype isolates, Czech Republic 2004

\begin{tabular}{|l|l|l|l|l|l|}
\hline $\begin{array}{l}\text { Geographic origin } \\
\text { of isolates }\end{array}$ & $\begin{array}{l}\text { All typed strains } \\
\text { (one per patient) }\end{array}$ & $\begin{array}{l}\text { All Beijing-genotype } \\
\text { isolates }\end{array}$ & $\begin{array}{l}\text { Beijing-genotype } \\
\text { isolates in clusters }\end{array}$ & $\begin{array}{l}\text { Foreign origin in patients } \\
\text { with Beijing-genotype } \\
\text { isolates }\end{array}$ & $\begin{array}{l}\text { Beijing-genotype isolates } \\
\text { with any drug resistance } \\
\text { (or MDR) }\end{array}$ \\
\hline Prague & 83 & 4 & 0 & 3 & $1(1)$ \\
\hline South Moravia & 37 & 5 & $5(2$ clusters) & 2 & $1(0)$ \\
\hline $\begin{array}{l}\text { Moravian-Silesian } \\
\text { region }\end{array}$ & 35 & 2 & 0 & 2 & $2(0)$ \\
\hline All & 155 & 11 & 5 & 6 & $4(1)$ \\
\hline & & $\begin{array}{l}7,1 \% \\
\text { of all isolates }\end{array}$ & $\begin{array}{l}45 \% \\
\text { of all Beijing-genotype } \\
\text { isolates }\end{array}$ & $\begin{array}{l}55 \% \\
\text { of all Beijing-genotype } \\
\text { isolates }\end{array}$ & $\begin{array}{l}36 \% \\
\text { of all Beijing-genotype } \\
\text { isolates }\end{array}$ \\
\hline
\end{tabular}

or INH+ RMP+SM+EMB ( $=1)$. By IS6110-RFLP, only the two INH+RMP+SM resistant isolates were clustered: They were isolated from an elder Czech and a young homeless Georgian patient, respectively, both from the Moravian-Silesian region, but not from the same district. Contact tracing information revealed that both had stayed in the same hospital at the same time. One INH-monoresistant isolate was identical by genotyping to a susceptible one from the same region, all other resistant isolates were unclustered. Seven resistant isolates were obtained from patients from the former Soviet Union and 4 from Czech citizens. The seven immigrants were younger than Czech patients with resistant TB (mean age 27 vs. 51 years; $p<0.01$ ). Furthermore, four patients with different resistant isolates lived in one home for asylum seekers in the Moravian-Silesian region. The location of this home is the reason that this region has a significantly higher proportion of resistant isolates than the other two regions $(14 \%$ vs. $4 \% ; p<0.05)$. Of altogether 11 Beijing-type isolates, 4 were associated with drug resistance, and all were isolated from immigrants from Eastern Europe (Table 4). In contrast, non-resistant Beijing-type isolates were only found in native Czech $(n=5)$ or Vietnamese $(n=2)$ individuals.

\section{DISCUSSION}

In terms of TB incidence, the Czech Republic can be regarded as in between the Western European countries and Eastern European former Soviet Union member states (7). As a Central Euopean country, the country is exposed to migration along the economical West-East divide and flight from warfare in former Soviet Union member states. These trends are considered to contribute in particular to the observed rise in drug resistant TB (13). The present study therefore encompassed for the first time the Moravian-Silesian region on the Czech-Ukrainian border with a state-operated home for asylum seekers, together with the urban area of Prague and the rural South Moravian region. Although representing only a circumscript period of time, the study allowed making qualitative and quantitative estimates of strain prevalence and respective changes to the situation several years before.

The IS6110-RFLP clustering analysis revealed $29 \%$ of isolates in clusters altogether and without significant differences between the three study regions. This is in keeping with the data presented by Kurepina et al. (21) which showed 32\% clustering for isolates from 1998 (28\% and 35\% in Prague and South Mora- via, respectively, compared to $30 \%$ for each of the two regions in 2004). Furthermore, native Czech patients have a relatively high mean age (54 yrs). The limited duration of the study does not allow to estimate the proportion of TB cases attributable to recent transmission, however, it suggests that recent transmission of TB is not a large problem in the Czech Republic. As might have been expected, some cluster patterns were found both in 1998 and 2004: Five out of nine Prague clusters in the 1998 analysis were seen again in 2004, comprising 58\% (in 1998) and 64\% (2004) of the Prague patients with clustered isolates, respectively, which is remarkable both in the extent and steadiness. In 2004, however, these clusters also included 7 isolates from outside Prague, suggesting an expansion from the capital to the other regions. Alternatively, keeping in mind the short and discontinuous observation period, these strains could have been circulating for a long time throughout the country: this hypothesis would be supported by the old age of native Czech TB patients, which is independent of cluster status (mean age 52 vs. 55 years in patients with clustered or unclustered isolates). On the contrary, there was little continuity between the cluster prototypes in South Moravia: of the 15 cluster prototypes in 1998, only the largest one, including patients from South Moravia and Prague at both sampling times, was present in 2004. All clusters in 2004 with isolates from South Moravia only, or from the Moravian-Silesian region only, were small (on average 2.2 patients including index case).

For the first time, the drug resistance status of prevalent isolates could be compared to the genotype on a national scale. Of 11 resistant isolates (5 MDR and 6 with any other resistance), only two were identical. As both had stayed in the same hospital at the same time, a transmission in either direction appears possible, whereas a laboratory contamination could be excluded. This low proportion of clustered resistant isolates may most likely be explained as a result of multiple individual treatment failure, or of multiple imports from abroad or other Czech regions, or of both. In this regard, the distribution of resistant and susceptible isolates of the Beijing genotype and the change of Beijing-type prevalence over time was assessed. All four resistant isolates found with immigrant Eastern Europeans had the Beijing-genotype, although clearly different by RFLP, and no further resistant Beijing-type isolate was identified. Such evidence for multiple, parallel import of MDR-Beijing type strains has been documented also in other Central European countries (13). The prevalence of the Beijing-type among Czech isolates appears to have increased 
from $3 \%$ in $1998(21)$ to $6.5 \%$ in this study. Whether the increased number of - susceptible - Beijing-type isolates in native Czech patients is merely the result of more than a decade of probably increased contact with such strains or reflects their postulated increased pathogenicity, cannot be decided in this place. Altogether, however, evidence can be demonstrated for the role of importation of resistant TB from Eastern Europe, which is often, but not always associated with the Beijing genotype. Other factors associated with MDR-TB like homelessness (23) or imprisonment appear to be of less importance in this study sample. Of the seven cases of TB in prisoners or homeless, all but one (a prisoner of Moldovan nationality with a double resistant isolate) had individual genotypes there were susceptible to first-line drugs. However, that these factors are relevant, has been documented earlier in the Czech Republic in an outbreak of MDR-TB comprising homeless, imprisoned, or immigrant patients in the Czech Republic (16).

The distribution of strain families in the M. tuberculosis population is apparently stable over the last years. Unsurprisingly, isolates of the Haarlem and T-family, respectively, were seen most often (Table 3). Other world-wide prevalent STs were rare, with the exception of the Beijing type. Noteably, a large number of individual STs $(n=45)$ was recorded, as was the case in 1998 (ref. 21). This adds to the evidence of a generally very heterogeneous M. tuberculosis population, interestingly without a single isolate of $M$. bovis or M. caprae among the 401 isolates in both studies. This is in contrast to the experience of Germany or Austria where rates around $0.5 \%$ of "bovine" isolates in humans have been observed $(11,28)$. Although M. caprae is a frequent cause of animal TB in Middle Europe $(6,24,25,29)$, bovine tuberculosis in cattle has apparently been decimated in the country very efficiently (26).

Finally, we compared the clustering results by the current TB fingerprinting standard technique, IS6110-RFLP, with those of the forthcoming standard, MIRU-VNTR genotyping (30, 31). All clusters formed by RFLP but one were distinguishable by MIRU-VNTR. Two large clusters separated by 2 "additional" out of 18 VNTR loci, supporting the need of more than the 12 canonical loci for population-based VNTR typing. On the other hand, the microheterogeneity in cluster $\mathrm{C} 12$ was only reflected by VNTR typing. We have not applied the MIRU-VNTR method to the RFLP-unclustered isolates, however, and the discrimination between those isolates has to be determined by future work. In studies conducted elsewhere, MIRU-VNTR was shown to discriminate sufficiently well between epidemiologically unrelated isolates $(22,31)$. We conclude that the VNTR data from this study are promising in connecting data from earlier and future studies on TB epidemiology from the Czech Republic and other European countries.

\section{Acknowledgements}

This study was inspired by the meetings of the European Union Concerted Action "New generation markers and techniques for the epidemiology and control of tuberculosis" (QLK2-CT-2000-00630). We thank Dr. Milan Šlosárek from the National Reference Laboratory of Mycobacterial Diseases for technical assistance and fruitful consultations and Prof. Ivo Pavlik, Veterinary Research Institute Brno, for many helpful discussions.

\section{REFERENCES}

1. Anh DD, Borgdorff MW, Van LN, Lan NT, van Gorkom T, Kremer K, et al. Mycobacterium tuberculosis Beijing genotype emerging in Vietnam. Emerg Infect Dis. 2000 May-Jun;6(3):302-5.

2. Tuberculosis and respiratory diseases 2004. Prague: Institute of Health Information and Statistics of the Czech Republic; 2005.

3. Annual report on the mycobacteriological diagnostics in the Czech and Slovak Republics. Acta Hyg Epidemiol Microbiol. 2005;4:1-36.

4. Brudey K, Driscoll JR, Rigouts L, Prodinger WM, Gori A, Al-Hajoj SA, et al. Mycobacterium tuberculosis complex genetic diversity: mining the fourth international spoligotyping database (SpolDB4) for classification, population genetics and epidemiology. BMC Microbiol. 2006 Mar $6 ; 6: 23$.

5. Dale JW, Brittain D, Cataldi AA, Cousins D, Crawford JT, Driscoll J, et al. Spacer oligonucleotide typing of bacteria of the Mycobacterium tuberculosis complex: recommendations for standardised nomenclature. Int J Tuberc Lung Dis. 2001 Mar;5(3):216-9.

6. Erler W, Martin G, Sachse K, Naumann L, Kahlau D, Beer J, et al. Molecular fingerprinting of Mycobacterium bovis subsp. caprae isolates from central Europe. J Clin Microbiol. 2004 May;42(5):2234-8.

7. EuroTB - Surveillance of Tuberculosis in Europe [homepage on the Internet]. Annual reports 1998, 1999, 2000, 2001, 2002, 2003 [cited 2006 Jun 14]. Saint-Maurice: EuroTB - Institut de Veille Sanitaire. Available from: http://www.eurotb.org.

8. Glynn JR, Whiteley J, Bifani PJ, Kremer K, van Soolingen D. Worldwide occurrence of Beijing/W strains of Mycobacterium tuberculosis: a systematic review. Emerg Infect Dis. 2002 Aug;8(8):843-9.

9. Kamerbeek J, Schouls L, Kolk A, van Agterveld M, van Soolingen D, Kuijper S, et al. Simultaneous detection and strain differentiation of Mycobacterium tuberculosis for diagnosis and epidemiology. J Clin Microbiol. 1997 Apr;35(4):907-14.

10. Kremer K, Glynn JR, Lillebaek T, Niemann S, Kurepina NE, Kreiswirth BN, et al. Definition of the Beijing/W lineage of Mycobacterium tuberculosis on the basis of genetic markers. J Clin Microbiol. 2004 Sep;42(9):4040-9.

11. Kubica T, Rusch-Gerdes S, Niemann S. Mycobacterium bovis subsp. caprae caused one-third of human M. bovis-associated tuberculosis cases reported in Germany between 1999 and 2001. J Clin Microbiol. 2003 Jul;41(7):3070-7.

12. Kubica T, Rusch-Gerdes S, Niemann S. The Beijing genotype is emerging among multidrug-resistant Mycobacterium tuberculosis strains from Germany. Int J Tuberc Lung Dis. 2004 Sep;8(9):1107-13.

13. Kubica T, Agzamova R, Wright A, Aziz MA, Rakishev G, Bismilda V, et al. The Beijing genotype is a major cause of drug-resistant tuberculosis in Kazakhstan. Int J Tuberc Lung Dis. 2005 Jun;9(6):646-53.

14. Kubín M, Riley LW, Havelková M, Poltoratskaia, Kocová A. Molecular epidemiology of tuberculosis in Prague: analysis by restriction fragment length polymorphism. Int J Infect Dis. 1998 Jan-Mar;2(3):155-8.

15. Kubín M, Prikazský V, Havelková M, Švandová E, Levina K, Kurve A, et al. Present state of tuberculosis in the Czech Republic and in central European and Baltic countries. Cent Eur J Public Health. 1999 Aug;7(3):109-15.

16. Kubín M, Havelková M, Hynčicová I, Švecová Z, Kaustová J, Kremer K, et al. The first occurrence of a multi-drug resistant tuberculosis epidemic in the Czech Republic caused by genetically closely related Mycobacterium tuberculosis strains. Cent Eur J Public Health. 2000 Feb;8(1):24-7.

17. Kubín M, Mezenský L, Prikazský V, Kremer K, van Soolingen D. Family outbreaks of tuberculosis in South Moravia, a low incidence area of the Czech Republic. Int J Tuberc Lung Dis. 2001 May;5(5):426-31.

18. Kubín M, Driscoll J, Polanecký V, Kozáková B, Zdražílek J, Mezenský L. Spoligotypes of Mycobacterium tuberculosis in the Czech population (methods and pilot study). Epidemiol Mikrobiol Imunol. 2002 Apr;51(2):52-9. (In Czech.)

19. Kubín M. The Mycobacterium tuberculosis Beijing genotype worldwide and in the Czech Republic. Epidemiol Mikrobiol Imunol. 2003 Apr.;52(2):84-6. (In Czech.)

20. Kubín M, Lillebaek T, Polanecký V, Kozáková B, Švecová Z, Papiková E, et al. Molecular epidemiology of tuberculosis among prisoners. Epidemiol Mikrobiol Imunol. 2003 Feb;52(1):3-8. (In Czech.) 
21. Kurepina NE, Kreiswirth BN, Shaskina E, Driscoll JR, Polanecký V, Kozáková B, et al. Molecular epidemiology of tuberculosis in Prague and South Moravia, Czech Republic: genetic analysis of Mycobacterium tuberculosis isolates by IS6110-RFLP fingerprinting and spoligotyping. Cent Eur J Public Health. 2004 Sep;12(3):141-50.

22. Mazars E, Lesjean S, Banuls AL, Gilbert M, Vincent V, Gicquel B, et al. High-resolution minisatellite-based typing as a portable approach to global analysis of Mycobacterium tuberculosis molecular epidemiology. Proc Natl Acad Sci USA. 2001 Feb 13;98(4):1901-6.

23. Moss AR, Hahn JA, Tulsky JP, Daley CL, Small PM, Hopewell PC. Tuberculosis in the homeless. A prospective study. Am J Respir Crit Care Med. 2000 Aug;162(2 Pt 1):460-4.

24. Pavlík I, Dvorská L, Bartoš M, Parmová I, Melichárek I, Jesenská A, et al. Molecular epidemiology of bovine tuberculosis in the Czech Republic and Slovakia in the period 1965-2001 studied by spoligotyping. Vet Med. 2002 Jul;47(7):181-94.

25. Pavlík I, Bureš F, Janovský P, Pečinka P, Bartoš M, Dvorská L, et al. The last outbreak of bovine tuberculosis in cattle in the Czech Republic in 1995 was caused by Mycobacterium bovis subspecies caprae. Vet Med. 2002 Sep;47(9):251-63.

26. Pavlik I. The experience of new European Union Member States concerning the control of bovine tuberculosis. Vet Microbiol. 2006 Feb 25;112(2-4):221-30.

27. Prikazský V, Kubín M, Pikhartová J. Selected results of the tuberculosis control program in the Czech Republic. Cent Eur J Public Health. 1999 Aug;7(3):116-21.
28. Prodinger WM, Eigentler A, Allerberger F, Schönbauer M, Glawischnig W. Infection of red deer, cattle, and humans with Mycobacterium bovis subspecies caprae in western Austria. J Clin Microbiol. 2002 Jun;4 0(6):2270-2.

29. Prodinger WM, Brandstätter A, Naumann L, Pacciarini M, Kubica T, Boschiroli ML, et al. Characterization of Mycobacterium caprae isolates from Europe by mycobacterial interspersed repetitive unit genotyping. J Clin Microbiol. 2005 Oct;43(10):4984-92.

30. Supply P, Lesjean S, Savine E, Kremer K, van Soolingen D, Locht C. Automated high-throughput genotyping for study of global epidemiology of Mycobacterium tuberculosis based on mycobacterial interspersed repetitive units. J Clin Microbiol. 2001 Oct;39(10):3563-71.

31. van Deutekom H, Supply P, de Haas PE, Willery E, Hoijng SP, Locht C, et al. Molecular typing of Mycobacterium tuberculosis by mycobacterial interspersed repetitive unit-variable-number tandem repeat analysis, a more accurate method for identifying epidemiological links between patients with tuberculosis. J Clin Microbiol. 2005 Sep;43(9):4473-9.

32. van Embden JD, Cave MD, Crawford JT, Dale JW, Eisenach KD, Gicquel B, et al. Strain identification of Mycobacterium tuberculosis by DNA fingerprinting: recommendations for a standardized methodology. J Clin Microbiol. 1993 Feb;31(2):406-9.

33. van Soolingen D. Molecular epidemiology of tuberculosis and other mycobacterial infections: main methodologies and achievements. J Intern Med. 2001 Jan;249(1):1-26.

Received March 16, 2006 Received in revised form and accepted June 30, 2006 